\title{
Tumor necrosis factor alpha in peripheral neuropathy in type 2 diabetes mellitus
}

\author{
Wafik M. El Sheikh', Ibrahim E. Alahmar ${ }^{1}$, Gelan M. Salem ${ }^{1 *}$ and Mohamed A. El-Sheikh²
}

\begin{abstract}
Objective: To compare serum levels of tumor necrosis factor alpha (TNF-a) between type 2 diabetes mellitus patients with and without peripheral neuropathy (PN). Also, to study the relation between peripheral nerves conduction velocity and serum level of TNF-a in those patients.

Patients and methods: This study included three groups with 40 patients in each group. Diabetic PN patients (groups I and II) were compared with diabetic patients without PN (group III). Groups I and II differed in the duration of clinical neuropathy with less than 5 years in group I and more than 5 years in group II.

All patients were subjected to general and neurological examination, neuropathy symptom score (NSS), neuropathy disability score (NDS), glycosylated hemoglobin ( $\mathrm{HbA1c}$ ), serum level of TNF-a and both sensory and motor nerve conduction study.
\end{abstract}

Results: This study showed raised serum levels of TNF-a in diabetic patients with PN, more with increased duration of neuropathy. TNF-a levels showed statistically significant negative correlation with nerve conduction velocity but positive correlations with each of neuropathy disability score, neuropathy symptom score, and glycosylated hemoglobin.

Conclusion: TNF-a might be involved in the pathogenesis of diabetic PN, and its serum level might be used as a biomarker for the severity of diabetic PN.

Keywords: Type 2 diabetes mellitus, Peripheral neuropathy, Nerve conduction velocity, TNF-a

\section{Introduction}

One of the common complications of diabetes is peripheral neuropathy (PN) affecting about $50 \%$ of diabetic patients $[1,2]$. It causes progressive degeneration of nerves, making it a big concern for clinicians [3]. Recent evidences show a relation between inflammation and diabetic PN [4].

Studies show that serum levels of tumor necrosis factor- $\alpha$ (TNF- $\alpha$ ) and soluble TNF- $\alpha$ receptors (sTNFR1 and sTNFR2) increased in patients with diabetic PN. Tumor necrosis factor- $\alpha$ is a pro-inflammatory cytokine, produced by activated macrophages and monocytes, that participates in the pathogenesis of diabetic PN [5-8].

Diabetic patients with prolonged hyperglycemia show dysregulation of TNF- $\alpha$ control due to associated metabolic derangements (increased polyol flux, accumulation

\footnotetext{
* Correspondence: d.gelan1981@gmail.com

${ }^{1}$ Neuro-Pscychiatry Department, Faculty of Medicine, Menoufia University,

Shibin Al Kawm, Egypt

Full list of author information is available at the end of the article
}

of advanced glycation end products, oxidative stress, and lipid alterations) [9-13].

In diabetic peripheral neuropathy patients, unmyelinated nerves undergo axonal loss while myelinated ones undergo demyelination. The demyelination is due to an immune response, where self-antigens activate $\mathrm{T}$ cells producing different cytokines, as TNF- $\alpha$, with potential positive feedback effect increasing its own immune response and finally mediating the inflammatory reaction $[7,14,15]$.

TNF- $\alpha$ also causes oligodendrocyte toxicity and demyelination. It increases secretion of IL-1 $\beta$ and IL- 6 and other inflammatory factors, from monocytes and endothelial cells, that enhance its effect indirectly [16].

Regarding blood vessels, TNF- $\alpha$ causes endothelial dysfunction and stenosis, hemodynamic abnormalities, decreased perfusion, and neurotrophic blood vessels damage as it increases several growth factors and cell adhesion molecules. It also inhibits the nitric oxide 
synthase (NOS) activity in vascular endothelial cell, resulting in a decrease of NOS-induced vasodilatation [17].

\section{Aim of the work}

1- Comparison between diabetic patients with and without PN regarding serum level of TNF- $\alpha$.

2- Study the relation between serum TNF- $\alpha$ level and nerve conduction velocity in diabetic patients.

\section{Patients and methods}

A community sample of 120 patients with the diagnosed of type 2 diabetes mellitus, with or without PN, was recruited from Benha Teaching Hospital diabetes outpatient clinic. Patients with acute diabetic complications (e.g., DKA), acute or chronic illnesses other than diabetes (e.g., liver cell failure), local or general causes that affect nerves (e.g., vasculitis), and non-consenting patients were excluded.

Patients were divided into three groups: group (I), 40 patients with motor or mixed sensorimotor PN of a duration less than 5 years; group (II), 40 patients with motor or mixed sensorimotor PN of a duration of 5-10 years; and group (III) (control group), 40 patients without clinical neuropathy.

All the patients were subjected to the following; (1) History and examination: both general and neurological. (2) Neuropathy symptom score (NSS): developed by Dyck, 2002. It comprises proximal and distal symptoms of muscle weakness, sensory disturbances (e.g., pain, numbness, unsteadiness in walking), and autonomic neuropathy (e.g., impotence, orthostatic hypotension, nocturnal diarrhea). Altogether, 17 symptoms are graded in the NSS: 1 point for the presence of a symptom and 0 if absent (mild symptoms $=3-4$, moderate symptoms $=$ $5-6$, severe neuropathic symptoms $=7-10$ ). (3) Neuropathy disability score (NDS): developed by Dyck, 1988. It evaluates cranial nerves and upper and lower limbs bilaterally. Impairment of sensation, muscle strength, and tendon reflexes are individually scored, and all scores are summed to give a composite score of neurological deficits (mild neuropathic deficits $=3-5$, moderate neuropathic deficits $=6-8$, severe neuropathic deficits $=9-$ 10). (4) Glycosylated hemoglobin (HbA1c) and (5) serum tumor necrosis alpha (TNF- $\alpha)$ : blood samples were collected from selected patients aseptically by venipuncture then allowed to clot, and the serum was separated from the clot as soon as possible. No additives or preservatives were used to maintain the integrity of the sample. The samples were stored frozen at or below $20^{\circ} \mathrm{C}$ in vials for storage. Human TNF-alpha ELISA in vitro enzyme-linked immunosorbent assay kit (Gen-Probe Diaclone) was used for the quantitative measurement of TNF- $\alpha$ in serum of selected subjects. (5) Nerve conduction study: performed using Neuroperfect software on windows based Computerized EMG/NCV/EP system (TruTrace NCV/EMG/EP system), band pass filter at room temperature. For motor nerves, a depolarizing square wave current was applied to the peripheral nerve to produce a compound muscle action potential (CMAP) due to summation of the activated muscle fibers. For sensory nerves, a propagated sensory nerve action potential (SNAP) was created in an analogous manner. Nerve conduction velocities were measured in the four limbs with standard surface stimulating and recording techniques. Electrodes were coated with electroconductive gel and held in place with adhesive tape. Patients avoided prior application of topical creams which may increase skin resistance to the applied current requiring stronger levels of electrical stimulation. Cold environment was avoided because cool peripheries $\left(<32{ }^{\circ} \mathrm{C}\right)$ slow the conduction velocity of nerves. Median, ulnar, common peroneal, and posterior tibial nerves were selected for motor nerve conduction study, and median and sural nerves were selected for sensory nerve conduction study.

The recording montage for motor nerve conduction study was belly tendon montage. Active electrode was placed on motor end plate of muscles (muscle belly), reference electrode placed on the associated tendon (distal to the muscle belly), and ground electrode placed on the dorsum of hand in upper limbs and on the dorsum of foot in lower limbs. The recording and stimulation sites for motor study were as follows: median nerve recorded from abductor pollicis brevis, while stimulated distally at wrist between the tendons of flexor carpi radialis and palmaris longus, and proximally above elbow medial to biceps tendon over the brachial pulse. Ulnar nerve was recorded from the abductor digiti minimi and stimulated distally at wrist just lateral to flexor carpi ulnaris tendon and proximally $5 \mathrm{~cm}$ below and above ulnar groove. Peroneal nerve was recorded from extensor digitorum brevis and stimulated distally at ankle between the tendons of tibialis anterior and extensor hallucis longus and proximally just below fibular head. Tibial nerve was recorded from abductor halluces and stimulated distally at the ankle just posterior to the medial malleolus and proximally at the knee in the middle of popliteal crease. Regarding sensory study, antidromic response was used. Sural nerve was stimulated $14 \mathrm{~cm}$ proximal to the recording electrode (below and behind lateral malleolus) over the postero-lateral aspect of the leg. Sensory median study: the same site of stimulation as motor study, while recorded from the digital nerves distally at middle or index finger. 
Data were analyzed using Statistical Program for Social Science (SPSS) version 18.0. Quantitative data were expressed as mean \pm standard deviation (SD). Qualitative data were expressed as frequency and percentage. The following tests were done: ANOVA with post hoc study, Chi-square $\left(\chi^{2}\right)$, Pearson's correlation coefficient $(r)$, and binary logistic regression tests.

\section{Results}

Eighty patients with clinical diabetic neuropathy (group I, II) were compared to 40 patients without clinical neuropathy (control group III). While the three groups were matched regarding age and sex, groups I and II were also matched regarding other clinical data (e.g., BMI, blood pressure) except for the duration of PN. Statistically significant differences were found between diabetic patients with $\mathrm{PN}$, groups 1 and 2, and patients without, group 3, regarding BMI and systolic and diastolic blood pressure (Table 1 ).

Groups (I) and (II) showed increased TNF- $\alpha$, when compared to group (III) ( $P$ value $<0.001)$. Compared to each other, group (II) showed increased TNF- $\alpha$ than group (I) $(P$ value $<0.001)$ (Table 2$)$.

Group (II) showed significant increase in glycosylated hemoglobin (HA1c) when compared to groups (I) and
(III) ( $P$ value $<0.001$ ), which showed no differences between each other (Table 2).

Serum TNF- $\alpha$ level, in diabetic PN patients, showed negative correlation with motor and sensory nerve conduction velocities but positive correlation with neuropathy disability score (NDS), neuropathy symptom score (NSS), and glycosylated hemoglobin (HbA1c) (Table 3).

Binary logistic regression analysis demonstrated that elevated serum level of TNF- $\alpha$ was an independent risk factor for diabetic neuropathy among diabetic patients with odds ratio 3.6 and CI (1.6-7.8) while HA1c, weight, systolic blood pressure, BMI, and diastolic blood pressure were dependent risk factors for diabetic neuropathy (Table 4).

\section{Discussion}

Peripheral neuropathy is a common complication of diabetes mellitus; it occurs in about half of diabetic patients [18]. The mechanism of PN has not yet been elucidated clearly. Researches have indicated that proinflammatory cytokines, as TNF- $\alpha$, play important roles in the pathogenesis of diabetic PN [19], the finding which the present study tried to address.

Table 1 Demographic and clinical characteristics of type 2 diabetic patients with and without peripheral neuropathy

\begin{tabular}{|c|c|c|c|c|c|c|}
\hline \multirow[t]{2}{*}{ Demographic data } & \multicolumn{2}{|l|}{ Patients group } & \multirow{2}{*}{$\begin{array}{l}\text { Control group } \\
\text { Group (III) } N=40\end{array}$} & \multicolumn{3}{|c|}{ Statistical analysis } \\
\hline & Group (I) $N=40$ & Group (II) $N=40$ & & $F / X^{2}$ & $P$ value & Post hoc \\
\hline \multicolumn{7}{|l|}{ Gender (No. \%) } \\
\hline Male & 17 (42.5\%) & $16(40 \%)$ & $20(50 \%)$ & 0.879 & 0.644 & \\
\hline Female & $23(57.5 \%)$ & $24(60 \%)$ & $20(50 \%)$ & & & \\
\hline Age (years) & & & & & & $0.06^{1}$ \\
\hline Mean \pm SD & $55.9 \pm 8.2$ & $59.3 \pm 7.7$ & $56.7 \pm 7.1$ & 2.16 & 0.12 & $0.65^{2}$ \\
\hline Range & $45.0-65.0$ & $49.0-68.0$ & $35.0-45$ & & & $0.12^{3}$ \\
\hline BMI (kg/m2) & & & & & & $0.55^{1}$ \\
\hline Mean \pm SD & $31.9 \pm 5.3$ & $32.7 \pm 6.3$ & $29.1 \pm 3.4$ & 5.40 & 0.006 & $0.006^{2}$ \\
\hline Range & $25.8-36.8$ & $25.8-39.8$ & $25.7-39.8$ & & & $0.002^{3}$ \\
\hline Systolic BP(mmHg) & & & & & & $0.53^{1}$ \\
\hline Mean \pm SD & $141.3 \pm 8.5$ & $142.6 \pm 9.7$ & $132.5 \pm 8.2$ & 15.5 & $<0.001$ & $<0.001^{2}$ \\
\hline Range & $130.0-155.0$ & $130.0-155.0$ & $120-144$ & & & $<0.001^{3}$ \\
\hline Diastolic BP (mmHg) & & & & & & $0.48^{1}$ \\
\hline Mean \pm SD & $86.3 \pm 8.1$ & $87.5 \pm 7.0$ & $82.7 \pm 5.7$ & 5.09 & 0.008 & $0.02^{2}$ \\
\hline Range & $80.0-95.0$ & $80.0-95.0$ & $75.0-90.0$ & & & $0.001^{3}$ \\
\hline \multicolumn{7}{|c|}{ Duration of neuropathy } \\
\hline Mean \pm SD & $3.8 \pm 0.5$ & $7.6 \pm 1.1$ & & $t$ test & $<0.001$ & \\
\hline Range & $3.0-4.5$ & $6.0-9.0$ & & 15.18 & & \\
\hline
\end{tabular}

$F$ ANOVA test, $X^{2}$ chi-square test, $B M l$ body mass index

$P$ value $<0.001$ highly significant, $P$ value $<0.05$ significant, $P$ value $>0.05$ non-significant

${ }^{1}$ Comparing group 1 and group 2

${ }^{2}$ Comparing group 1 and group 3

${ }^{3}$ Comparing group 2 and group 3 
Table 2 Tumor necrosis factor alpha (TNF-a) and glycosylated hemoglobin (HA1C) in type 2 diabetic patients with and without peripheral neuropathy

\begin{tabular}{|c|c|c|c|c|c|c|}
\hline & Group (I) & Group (II) & Group (III) & $F$ & $P$ value & Post hoc \\
\hline TNF-a (pg/ml) & & & & & & $<0.001^{1}$ \\
\hline Mean \pm SD & $55.22 \pm 12.80$ & $77.31 \pm 19.31$ & $27.26 \pm 16.66$ & 40.14 & $<0.001$ & $<0.001^{2}$ \\
\hline Range & $43.73-68.65$ & 57.05-96.06 & $11.27-43.33$ & & & $<0.001^{3}$ \\
\hline $\mathrm{HbA} 1 \mathrm{c}$ & & & & & & $0.001^{1}$ \\
\hline Mean \pm SD & $7.54 \pm 0.60$ & $8.38 \pm 0.69$ & $7.40 \pm 0.48$ & 31.48 & $<0.001$ & $0.31^{2}$ \\
\hline Range & $6.77-8.56$ & $7.1-9.3$ & $6.68-8.0$ & & & $0.001^{3}$ \\
\hline
\end{tabular}

$F$ ANOVA test. $P$ value $<0.001$ highly significant

${ }^{1}$ Comparing group 1 and group 2

${ }^{2}$ Comparing group 1 and group 3

${ }^{3}$ Comparing group 2 and group 3

In this study, there was no statically significant difference between patients with neuropathy of short duration (group I) and patients without (group III) regarding glycosylated hemoglobin, but patients with neuropathy of longer duration (group II) show statically significant increase in glycosylated hemoglobin in comparison to both groups I and III. Despite that groups I and III did not show significant differences regarding glycosylated hemoglobin, patients in group I developed neuropathy while those in group III did not. Factors other than blood sugar level like genetic predisposition, elevated blood glucose, fat or protein metabolism abnormality, and vascular changes may contribute to the development of PN [20-22].

In the present study, statistical significant differences in blood pressure and body mass index were found between patients with PN (groups I and II) and patients without (group III). Furthermore, BMI and systolic and diastolic blood pressure were found to be dependent risk

Table 3 Correlation between serum levels of tumor necrosis factor (TNF-a) and nerve conduction velocity, clinical, and lab. data in type 2 diabetes mellitus

\begin{tabular}{|c|c|c|c|c|}
\hline & \multicolumn{4}{|c|}{ Serum level (TNF-a) } \\
\hline & \multicolumn{2}{|c|}{ Group 1} & \multicolumn{2}{|l|}{ Group 2} \\
\hline & $R$ & $P$ value & $R$ & $P$ value \\
\hline Median nerve (M) & -0.35 & 0.008 & -0.650 & $<0.001$ \\
\hline Ulnar nerve & -0.51 & 0.001 & -0.46 & 0.002 \\
\hline CPN nerve & -0.23 & 0.03 & -0.25 & 0.02 \\
\hline PTN nerve & -0.20 & 0.04 & -0.21 & 0.04 \\
\hline Median nerve(S) & -0.26 & 0.01 & -0.36 & 0.007 \\
\hline Sural nerve & -0.33 & 0.004 & -0.22 & 0.03 \\
\hline Neuropathy disability score & 0.829 & $<0.001$ & 0.50 & 0.001 \\
\hline Neuropathy symptom score & 0.53 & $<0.001$ & 0.38 & 0.004 \\
\hline $\mathrm{HbA1c}$ & 0.45 & 0.002 & 0.41 & 0.005 \\
\hline
\end{tabular}

CPN common peroneal nerve, PTN posterior tibial nerve, $M$ motor, $S$ sensory, HbA1c glycosylated hemoglobin, $r$ Pearson's correlation coefficient

$P$ value $<0.05$ significant. $P$ value $<0.001$ highly significant. Groups $I$ and $\|=$ diabetic PN patients factors for diabetic PN which was consistent with (Thomson et al., Juhani Partanen et al.) [23, 24]. According to Smith and Singleton, obesity and hypertriglyceridemia significantly increase risk for PN [25]. Studies stressed on the necessity of control of blood sugar, blood pressure, blood lipids, neurotrophic factors, antioxidants, and improvement of microcirculation during the treatment of diabetic PN [20-22, 26].

A significant increase of serum TNF- $\alpha$ level was found in patients with diabetic PN compared to patients without. Furthermore, TNF- $\alpha$ was found to be an independent risk factor for PN among diabetic patients type II. A finding was supported by the study of Skundric and Lisak and Navarro and Mora [27, 28], who asserted the role of this cytokine in the development diabetic PN. According to Pickup et al. and Shoelson et al. [29, 30], TNF- $\alpha$ significantly increases in non-insulin diabetes mellitus (NIDDM) patients. Satoh et al. [31] stated that TNF- $\alpha$ inhibits tyrosine kinase activity at the insulin receptors in obese subjects causing insulin resistance.

Recent evidence has shown that diabetic neuropathy is an autoimmune disorder with genetic background. Under normal conditions, the blood-nerve barrier maintains the circulating $\mathrm{T}$ cells in the immune tolerance state, but long-term hyperglycemia can damage this vascular barrier. Myelin protein glycosylation changes its antigenicity, making it vulnerable to the phagocytic attack of monocytes, macrophages, and neutrophils from blood circulation and tissue, and glial cells from nervous system that specifically recognize the glycosylated myelin antigen. In addition, the activated immune cells secrete cytokines such as TNF- $\alpha$ and IL-1 $\beta$, which impart toxic effects on neurons and glial cells, leading to demyelination. The stimulated monocytes and endothelial cells have a positive feedback loop for secretion of inflammatory substances that potentiate nerve damage $[32,33]$.

Previous studies have proposed that TNF- $\alpha$ stimulates the expression of specific proteins relevant to cellular damage, such as aldose reductase, protein kinase $\mathrm{C}$, mitogen-activated protein kinase, and inducible nitric 
Table 4 Multivariate logistic regression analysis of risk factors for diabetic neuropathy

\begin{tabular}{|c|c|c|c|c|c|c|}
\hline & SE & Wald $x^{2}$ & $P$ value & Odds ratio & \multicolumn{2}{|c|}{ 95\% Cl (lower-upper) } \\
\hline TNF-a (pg/ml) & 0.23 & 6.5 & 0.006 & 3.6 & 1.6 & 7.8 \\
\hline $\mathrm{HbA1c}$ & 0.77 & 3.34 & 0.03 & 1.95 & 1.12 & 5.66 \\
\hline Weight & 0.08 & 6.70 & 0.11 & 1.23 & 1.01 & 5.32 \\
\hline Systolic blood pressure & 0.09 & 1.63 & 0.09 & 1.01 & 0.23 & 4.33 \\
\hline BMl & 0.97 & 2.76 & 0.09 & 0.99 & 0.75 & 13.28 \\
\hline Diastolic blood pressure & 0.12 & 0.89 & 0.45 & 0.99 & 0.44 & 7.65 \\
\hline
\end{tabular}

Cl 95\% confidence interval

oxide synthase. All of which potentially play a role in the pathogenesis of diabetic polyneuropathy [34]. It is also proved that TNF- $\alpha$ can regulate the apoptosis of nerve cells in diabetic neuropathy which is crucial in the process of DPN [35]. Furthermore, TNF alpha as a pro-inflammatory cytokine has been involved in hyperalgesia and ectopic firing of sensory neurons [36].

In the present study, positive correlations were found between serum TNF- $\alpha$ and both neuropathy disability score (NDS) and neuropathy symptom score (NSS) were found. Also, the increase in serum TFN- $\alpha$ level was found to be a predictor of the increase of both neuropathy symptom score (NSS) and neuropathy disability score (NDS) in diabetic patients with peripheral neuropathy.

These results are supported by those of Festa et al. and Spranger et al. [37, 38] and Hussain et al. [18] who found that more severe diabetic neuropathy occurred in patients with increased levels of TNF- $\alpha$. According to Goldberg [39], increased TFN- $\alpha$ levels were found with neuropathy, nephropathy, retinopathy, and cardiovascular disease in both type 1 and type 2 diabetes. In Festa et al., Flyvbjerg, and Jung et al.'s [37, 40, 41] study, increase in serum cytokines was associated with the presence of neuropathy in diabetic patients especially with longer duration (more than 5 years) which coincides with the findings of the present study.

In the present study, positive correlations were found between serum TNF- $\alpha$ levels and glycosylated hemoglobin. This result agreed with Nieto-Vazquez et al. [42] and Rajarajeswari et al.'s [43] results where TNF- $\alpha$ levels correlated positively with glycosylated hemoglobin. According to Rajarajeswari et al., a relation between serum TNF- $\alpha$ levels and the degree of obesity was found.

In this study, there was a negative correlation between serum level of TNF- $\alpha$ and nerve conduction velocity (NCV) of motor and sensory nerves. This goes with Matsuda et al. [44] who showed significant negative correlation of TNF- $\alpha$ with sensory nerve conduction velocity. Again, Sumner et al. [34] and Ariyan and Brady [45] reported that this cytokine level may affect the nerve function. On contrast, EL-Badawy et al. found nonsignificant negative correlation with conduction velocity of motor and sensory nerves of upper and lower limbs. This difference may be due to that the patients in EL-Badawy et al.'s study were $65 \%$ mixed axonal and demyelinating neuropathy and $35 \%$ only demyelinating neuropathy [46].

Again, our result differs from the results of Duksal et al. who found no correlations between TNF- $\alpha$ levels and conduction velocities in the studied nerves [47], but who assessed only dorsal sural and medial planter sensory nerves in their study.

Diabetic PN patients nerve biopsy has shown that advanced glycation end products are deposited in the axons and myelin sheath [16], and these products increase macrophage phagocytosis of nerve myelin by elevating the expression of a number of nuclear factors as NF-kB-mediated inflammatory response genes, preventing $\mathrm{NO}$-dependent vasodilatation and anticoagulation, resulting in segmental demyelination of the nerve cells [16].

As with all studies, there are some limitations. First, small number of patients was included in the study. Second, the study assessed the conduction velocity relation with TNF alpha but not other parameters of nerve conduction study as amplitude of action potentials so the study did not assess axonal neuropathy. As such, larger studies that include both axonal and demyelinating neuropathy are needed in the future.

\section{Conclusion}

Serum level of TNF- $\alpha$ was found to be increased in diabetic PN patients, and its level was positively correlated with neuropathy symptoms and disability and negatively correlated with nerve conduction velocity. Elevated serum level of TNF- $\alpha$ was independent risk factor for diabetic neuropathy among diabetic patients. TNF- $\alpha$ might be involved in the pathogenesis of diabetic PN, and its serum level might be used as biomarker for the severity of diabetic PN.

\section{Recommendations}

1- All patients with diabetes should be screened for diabetic peripheral neuropathy at diagnosis of diabetes and periodically. 
2- Measurement of serum tumor necrosis factor alpha in type II diabetes as early predictor of peripheral neuropathy.

3- Larger studies should be done on the role of tumor necrosis factor alpha in diabetic patients including large number of patients and type I diabetes.

\section{Acknowledgements}

Not applicable.

\section{Funding}

Nil.

\section{Availability of data and materials}

All data and materials are available upon request submitted to the corresponding author, on the following e-mail: gehan.salim@med.menofia. edu.eg.,d.gelan1981@gmail.com.

\section{Authors' contributions}

All authors participated in the concept and design of the study. MAA is responsible for coordination and recruitment of participants and helped in the clinical examination. GMS participated in the concept and design of the study and analysis of data, helped in applying the inclusion and exclusion criteria, helped in drafting the manuscript, and performed the statistical analysis. All authors read and approved the final manuscript.

\section{Ethics approval and consent to participate}

The study was approved by Menofia University Faculty of Medicine Ethical Committee on,9-9- 2014. Written informed consents were obtained from all participants.

\section{Consent for publication}

Not applicable.

\section{Competing interests}

The authors declare that they have no competing interests.

\section{Publisher's Note}

Springer Nature remains neutral with regard to jurisdictional claims in published maps and institutional affiliations.

\section{Author details}

${ }^{1}$ Neuro-Pscychiatry Department, Faculty of Medicine, Menoufia University,

Shibin Al Kawm, Egypt. ${ }^{2}$ Benha Mental Health Hospital, Banha, Egypt.

Received: 29 September 2017 Accepted: 22 April 2019

Published online: 06 June 2019

\section{References}

1. Wooten K. Clinical features and electrodiagnosis of diabetic peripheral neuropathy in the dysvascular patient. Phys Med Rehabil Clin N Am. 2009; 20:657-76.

2. Tesfaye S, Selvarajah D. Advances in the epidemiology, pathogenesis and management of diabetic peripheral neuropathy. Diabetes Metab Res Rev. 2012;28(Suppl 1):8-14

3. Boulton AJ, Vinik Al, Arezzo JC, Bril V, Feldman EL, Freeman R, et al. Diabetic neuropathies: a statement by the American Diabetes Association. Diabetes Care. 2005;28:956-62.

4. Shi X, Chen Y, Nadeem L, Xu G. Beneficial effect of TNF-a inhibition on diabetic peripheral neuropathy. J Neuroinflammation. 2013;10:69.

5. Schram MT, Chaturvedi N, Schalkwijk CG, Fuller JH, Stehouwer CD. Markers of inflammation are cross-sectionally associated with microvascular complications and cardiovascular disease in type 1 diabetes-the EURODIAB Prospective Complications Study. Diabetologia. 2005;48:370-8.

6. Zoppini G, Faccini G, Muggeo M, Zenari L, Falezza G, Targher G. Elevated plasma levels of soluble receptors of TNF-alpha and their association with smoking and microvascular complications in young adults with type 1 diabetes. J Clin Endocrinol Metab. 2001;86:3805-8.
7. Gonzalez-Clemente JM, Mauricio D, Richart C, Broch M, Caixas A, Megia A, et al. Diabetic neuropathy is associated with activation of the TNF-alpha system in subjects with type 1 diabetes mellitus. Clin Endocrinol. 2005;63: 525-9.

8. Moriwaki Y, Yamamoto T, Shibutani Y, Aoki E, Tsutsumi Z, etal TS. Elevated levels of interleukin-18 and tumor necrosis factor-[alpha ] in serum of patients with type 2 diabetes mellitus: relationship with diabetic nephropathy. Metab Clin Exp. 2003;52:605-8.

9. Mather KJ, Funahashi T, Matsuzawa Y, Edelstein S, Bray GA, Kahn SE, et al. Adiponectin, change in adiponectin, and progression to diabetes in the Diabetes Prevention Program. Diabetes. 2008:57:980-6.

10. Pradhan AD, Manson JE, Rifai N, Buring JE, Ridker PM. C-reactive protein, interleukin 6, and risk of developing type 2 diabetes mellitus. JAMA. 2001; 286:327-34

11. Petersen KF, Shulman Gl. Etiology of insulin resistance. Am. J. Med. 2006;119: S10-6.

12. Goldfine A, Patti ME, O'Shea S, Kolberg J, Gerwien R, McKenna M. Protein biomarkers in fasting serum samples correlate with diabetes risk factors (abstract). Diabetes. 2008;57:A410.

13. Dyck PJ, Davies JL, Clark VM, Litchy WJ, Dyck PJ, Klein CJ, et al. Modeling chronic glycemic exposure variables as correlates and predictors of microvascular complications of diabetes. Diabetes Care. 2006;29:2282-8.

14. Boulton AJ, Malik RA, Arezzo JC, Sosenko JM. Diabetic somatic neuropathies. Diabetes Care. 2004;27:1458-86.

15. Sinnreich M, Taylor BV, Dyck PJ. Diabetic neuropathies. Classification, clinical features, and pathophysiological basis. Neurologist. 2005;11:63-79.

16. Fromont A, De Seze J, Fleury MC, Maillefert JF, Moreau T. Inflammatory demyelinating events following treatment with anti-tumor necrosis factor. Cytokine. 2009;45:55-7.

17. Estrella JS, Nelson RN, Sturges BK, Vernau KM, Williams DC, LeCouteur RA, et al. Endoneurial microvascular pathology in feline diabetic neuropathy. Microvasc Res. 2008:75:403-10.

18. Hussain G, Rizvi SAA, Singhal S, Zubair M, Ahmad J. Serum levels of TNF-a in peripheral neuropathy patients and its correlation with nerve conduction velocity in type 2 diabetes mellitus. Diabetes Metab Syndr. 2013;7(4):238-42.

19. Rahman MH, Jha MK, Suk K. Evolving insights into the pathophysiology of diabetic neuropathy: implications of malfunctioning glia and discovery of novel therapeutic targets. Curr Pharm Des. 2016;22(6):738-57.

20. Harati Y. Diabetic neuropathies: unanswered questions. Neurol Clin. 2007;25: 303-17.

21. Tesfaye S, Chaturvedi N, Eaton SE, Ward JD, Manes C, lonescu-Tirgoviste C, et al.: Vascular risk factors and diabetic neuropathy. N Engl J Med 2005, 352: 341-350.

22. Tavakkoly-Bazzaz J, Amoli MM, Pravica V, Chandrasecaran R, Boulton AJ, Larijani B, Hutchinson IV. VEGF gene polymorphism association with diabetic neuropathy. Mol Biol Rep. 2010;37:3625-30.

23. Partanen J, Niskanen L, Lehtinen J, Mervaala E, Siitonen O, Uusitupa M. Natural history of peripheral neuropathy in patients with non-insulin dependent diabetes mellitus. N Engl J Med. 1995:333(2):89-94.

24. lida KT, Shimano H, Kawakami Y, Sone H, Hideo Toyoshima H, Suzuki S, et al. Insulin up-regulates tumor necrosis factor-a production in macrophages through an extracellular-regulated kinase-dependent pathway. J Biol Chem. 2001:276(35):32531-7.

25. Smith AG, Singleton JR. Obesity and hyperlipidemia are risk factors for early diabetic neuropathy. J Diabetes Complicat. 2013;27(5):436-42.

26. Miranda-Massari JR, Gonzalez MJ, Jimenez FJ, Allende-Vigo MZ, Duconge J. Metabolic correction in the management of diabetic peripheral neuropathy: improving clinical results beyond symptom control. Curr Clin Pharmacol. $2011 ; 6: 260-73$

27. Skundrik DS, Lisak RP. Role of neuropoitic cytokines in development and progression of diabetic polyneuropathy: from glucose metabolism to neurodegeneration. Experimental Diabetology. 2003;4:303-12.

28. Navarro JF, Mora C. Diabetes, inflammation, proinflammatory cytokines, and diabetic nephropathy. TheScientificWorldJournal. 2006;6:908-17.

29. Pickup JC, Chusney GD, Thomas SM, Burt D. Plasma interleukin-6, tumour necrosis factor a and blood cytokine production in type 2 diabetes. Life Sci. 2000;67(3):291-300.

30. Shoelson SE, Herrero L, Naaz A. Obesity, inflammation, and insulin resistance. Gastroenterology. 2007;132(6):2169-80.

31. Satoh J, Yagihashi S, Toyota T. The possible role of tumor necrosis factor-a in diabetic polyneuropathy. J Diabetes Res. 2003;4(2):65-71. 
32. Said G, Lacroix C, Lozeron P, Ropert A, Plante V, Adams D. Inflammatory vasculopathy in multifocal diabetic neuropathy. Brain. 2003;126:376-85.

33. Gundogdu BM. Diabetic peripheral neuropathy: an update on pathogenesis and management. Curr Neurol Neurosci Rep. 2006;6:1-4.

34. Sumner C, Sheth S, Griffin JW, Cornblath DR, Polydefkis M. The spectrum of neuropathy in diabetes and impaired glucose tolerance. Neurology. 2003; 60(1):108-11.

35. Skundric DS, Lisak RP. Role of neuropoietic cytokines in development and progression of diabetic polyneuropathy: from glucose metabolism to neurodegeneration. Exp Diabesity Res. 2003;4(4):303-12.

36. Purwata TE. High TNF-alpha plasma levels and macrophages iNOS and TNFalpha expression as risk factors for painful diabetic neuropathy. J Pain Res. 2011:4:169-75

37. Festa A, D'Agostino R, Tracy RP, Haffner SM. Elevated levels of acute-phase proteins and plasminogen activator inhibitor-1 predict the development of type 2 diabetes the insulin resistance atherosclerosis study. Diabetes. 2002; 51(4):1131-7.

38. Spranger J, Kroke A, Möhlig M, Hoffmann K, Bergmann MM, Ristow M, et al. Inflammatory cytokines and the risk to develop type 2 diabetes results of the prospective population-based European Prospective Investigation into Cancer and Nutrition (EPIC)-Potsdam Study. Diabetes. 2003;52(3):812-7.

39. Goldberg RB. Cytokine and cytokine-like inflammation markers, endothelia dysfunction, and imbalanced coagulation in development of diabetes and its complications. J. Clin. Endocrinol. Metab. 2009;94(9):3171-82.

40. Flyvbjerg A. Diabetic angiopathy, the complement system and the tumor necrosis factor superfamily. Nat Rev Endocrinol. 2010;6(2):94-101.

41. Jung, C.-H., Kim, B.-Y., Mok, J.-O., Kang SK, Kim CH: Association between serum adipocytokinelevels and microangiopathies in patients withtype 2 diabetes mellitus. J Diabetes Invest, 2014;5:333-33.

42. Nieto-Vazquez, I., Fernández-Veledo, S., Krämer, D. K., Vila-Bedmar R, GarciaGuerra L, Lorenzo M.: Insulin resistance associated to obesity: the link TNFalpha. Arch Physiol Biochem, 2008;114(3):183-194.

43. Rajarajeswari, D., Ramlingam, K. Naidu JN. Tumour necrosis factor alpha in development of insulin resistance in type II diabetes. International Journal of Applied Biology and Pharmaceutical Technology. 2011;(1):55-60.

44. Matsuda M, Kawasaki F, Inoue H, Kanda Y, Yamada K, Harada Y, et al. Possible contribution of adipocytokines on diabetic neuropathy. Diabetes Res Clin Pract. 2004;66:S121-3.

45. Ariyan CE, Brady MS. History of regional chemotherapy for cancer of the extremities. Int J Hyperth. 2008;24(3):185-92.

46. El-Badawy MA, Farrag DA, Abd El-Rehem SM, El-Mahdi AR, El-Sherbeny AA Abdel Hady EA, Abdel-Sattar HA, Abdelaziz DM. Tumor necrosis factor-a is a novel biomarker for peripheral neuropathy in type II diabetes mellitus: a clinical and electrophysiological study. Egypt Rheumatol Rehabil. 2017;44: 83-90.

47. Duksal T, Tiftikcioglu BI, Bilgin S, Kose S, Zorlu Y. Role of inflammation in sensory neuropathy in prediabetes or diabetes. Acta Neurol Scand. 2015; 133:384-90.

\section{Submit your manuscript to a SpringerOpen ${ }^{\circ}$ journal and benefit from:}

- Convenient online submission

- Rigorous peer review

- Open access: articles freely available online

- High visibility within the field

- Retaining the copyright to your article

Submit your next manuscript at $\boldsymbol{\nabla}$ springeropen.com 